Review Paper:

\title{
The Effectiveness of Noise Reduction Interventions in Neonatal Intensive Care Units
}

\author{
Nasrin Gholami ${ }^{1}$ (D), Leili Borimnejad ${ }^{2 *}$ (D), Reza Jafari ${ }^{3}$ \\ 1. Department of Neonatal and Pediatric Nursing, School of Nursing \& Midwifery, Iran University of Medical Sciences, Tehran, Iran. \\ 2. Nursing Care Research Center, Iran University of Medical Sciences, Tehran, Iran. \\ 3. Department of Medical Immunology, School of Medical, Shahroud University of Medical Sciences, Shahroud, Iran.
}

\begin{tabular}{|l|l|}
\hline $\begin{array}{c}\text { Use your device to scan } \\
\text { and read the article online }\end{array}$ & $\begin{array}{l}\text { Citation: Gholami, N., Borimnejad, L., Jafari, R., 2020. The Effectiveness of Noise Reduction Interventions in Neonatal } \\
\text { Intensive Care Units. Journal of Client-Centered Nursing Care, 6(1), pp. 1-6. https://doi.org/10.32598/JCCNC.6.1.169.6 }\end{array}$ \\
\hline
\end{tabular}

\section{(c) (1) (s)}

Article info:

Received: 10 Aug 2019

Accepted: 25 Dec 2019

Published: 01 Feb. 2020

Keywords:

Noise, Reduction interventions, Neonatal intensive care

\begin{abstract}
A B S T RA C T
Background: Loud noise in the Neonatal Intensive Care Units (NICU) has negative effects on the health and wellness of hospitalized preterm infants. Various technologies for the care of preterm infants, extensive therapeutic interventions, and communication between staff are among the causes of loud noise in these wards. This review article aims to evaluate the effectiveness of noise reduction interventions in NICUs.

Methods: A literature search was conducted 2012-2020 in Medline, Embase, CINAHL, SID IranDoc, and Magiran databases. The search words were preterm infant, noise, and neonatal intensive care unit. Interventional and quasi-experimental papers were included in this review. A total of 26 articles were analyzed regarding the noise levels, effects of noise enhancement, and noise reduction interventions. The exclusion criteria were duplicate texts, non-English/Persian articles, editorials, letters, patents, errata, meeting abstracts, and conference papers. Systematic reviews and meta-analyses methodology was followed to perform the review.
\end{abstract}

Results: The results showed that the sound levels in the NICUs were higher than those mentioned by the WHO standard. The study articles reported personnel training as an effective intervention in noise reduction. But even with the proper training, there were very few changes in the sound levels. The noise level had been reduced to $3-4 \mathrm{~dB}$, and even increased in some cases due to the impossibility of changing the structure of the NICU and changing the existing devices.

Conclusion: Education is the most effective way to reduce noise. To make noise reduction possible, personnel training is essential as the first step. Sound levels must be measured to control the volume NICUs should be designed with separate beds and acoustic incubators should be used.

\footnotetext{
* Corresponding Author:

Leili Borimnejad, PhD.

Address: Nursing Care Research Center, Iran University of Medical Sciences, Tehran, Iran.

Tel: +98 (912) 5029548

E-mail: borimnejad.l@iums.ac.ir
} 


\section{Highlights}

- Despite many efforts and interventions conducted, the noise level in NICUs is still above the standard level.

- The most effective way to reduce noise is to provide continuous training to the personnel.

- To achieve sustainable results, changing culture is necessary.

\section{Plain Language Summary}

This study aimed to investigate the effectiveness of noise reduction methods in neonatal intensive care units. To achieve the goal, 26 interventional articles in English/Persian language were examined in a 10-year period. The results showed that the noise level in these units is higher than the standard. Most studies have focused on staff training. Studies have yielded conflicting results and in some cases, staff training was not enough to reduce noise. Therefore, there is a need to continue education for personnel and all clients in these units. The change in the physical structure and culture of the department staff helps to sustain the results of noise reduction measures. Future studies are needed to discover new solutions to this old problem.

\section{Introduction}

ound is produced by air vibration and exists in all areas of life. Loud noise has harmful effects on both neonates and medical staff (Carvalhais et al. 2018). A great deal of research has focused on identifying and creating the ideal Neonatal Intensive Care Unit (NICU) environment (Meredith, Jnah \& Newberry 2017). Specifically, attention has been dedicated to monitoring and regulating the acoustic environment in the NICU (Smith, Ortmann \& Clark 2018).

Cochlear development and the growth of other terminal sensory organs occur in the $24^{\text {th }}$ week of fetal life. Consequently, premature neonates hear sounds nearly similar to normal infants (Eggermont 2017). The range of hearing stimulation threshold in the $28-27$ week is $40 \mathrm{~dB}$ and reaches $13.5 \mathrm{~dB}$ at 42 weeks of gestation, indicating continued evolution of the auditory nerve pathway through the term (Manske 2017; Santos et al. 2018).

The American Academy of Pediatrics (AAP) recommends that the noise level should not exceed $45 \mathrm{~dB}$ in NICUs and the US Environmental Protection Agency recommends that noises should be raised to $45 \mathrm{~dB}$ for the comfort and recovery of infants (Aggarwal et al. 2019). Despite these recommendations, existing analyses of the acoustic environment in the NICU have indicated that these noise standards are being violated regularly (Knutson 2012).

Studies show that the average noise level in NICUs is 50-75 dB and reaches $105 \mathrm{~dB}$ at most. Although the bene- fits of noise reduction for neonates have been established, there is still no appropriate way to its implementation in the noisy parts of NICUs (Almadhoob \& Ohlsson 2015).

Many recent studies have shown the need for sound reduction interventions to improve the environmental conditions of NICUs.

Two systematic reviews with 5 years apart have been conducted on sound reduction interventions (Almadhoob \& Ohlsson 2015). Many studies have suggested different ways to manage harmful sounds and obtained different results (Abdeyazdan, Ghassemi \& Marofi 2014; Calikusu Incekar \& Balci 2017; Fernández Zacarías et al. 2018)

Because of the rising trend of preterm births on the one hand, and the increased survival of these infants thanks to advances in technology and improved care, on the other hand, the importance of caring for these infants in a safe environment and treating them with minimal complications is paramount.

This review article aims to evaluate the effectiveness of noise reduction interventions in neonatal intensive care units.

\section{Materials and Methods}

This review was performed according to Preferred Reporting Items for Systematic Reviews and Meta-Analyses (PRISMA) guidelines for reporting on systematic reviews. 
Table 1. The results of the literature review

\begin{tabular}{|c|c|c|c|c|}
\hline Results & Intervention & Publication (y) & Authors & Objective \\
\hline $\begin{array}{c}\text { Noise reduction from } 62.4 \text { to } 56.1 \\
\mathrm{~dB} \\
\text { Noise levels declined compared } \\
\text { to pre-intervention but remained } \\
\text { above standard levels }\end{array}$ & $\begin{array}{l}\text { Multiple noise reduction } \\
\text { strategies were tested through } \\
\text { Plan-Do-Study-Act cycles based } \\
\text { on the Institute for Healthcare } \\
\text { Improvement model for im- } \\
\text { provement. Strategies targeted } \\
\text { environmental and behavioral } \\
\text { modifications. }\end{array}$ & 2017 & $\begin{array}{c}\text { Mohamed Farooq } \\
\text { Ahamed, Deborah } \\
\text { Campbell, Susan } \\
\text { Horan, } \\
\text { and Orna Rosen }\end{array}$ & $\begin{array}{c}\text { To lower the } \\
\text { mean ambient } \\
\text { noise level within } \\
\text { a level IV neo- } \\
\text { natal Intensive } \\
\text { Care Unit (NICU) } \\
\text { by } 10 \% \text { from the } \\
\text { baseline in one } \\
\text { year. }\end{array}$ \\
\hline $\begin{array}{c}\text { Reduced sound levels from } 55-100 \\
\text { dB to } 46.3 \mathrm{~dB} \text { to create a "quiet } \\
\text { time" }\end{array}$ & $\begin{array}{l}\text { Evaluate nurses' views on noise } \\
\text { in the NICU, measure sound } \\
\text { levels, evaluate and compare } \\
\text { sound levels with standard lim- } \\
\text { its, implement quiet hour pro- } \\
\text { tocol, make structural changes } \\
\text { and section equipment }\end{array}$ & 2014 & $\begin{array}{l}\text { Vickie Laubach, } \\
\text { Patricia Wilhelm, } \\
\text { Katie Carter }\end{array}$ & $\begin{array}{l}\text { Shhh. I'm Grow- } \\
\text { ing: Noise } \\
\text { in the NICU }\end{array}$ \\
\hline $\begin{array}{l}\text { Decreasing sounds in some places } \\
\text { and increasing in others }\end{array}$ & $\begin{array}{l}\text { Implementation of inter- } \\
\text { ventions in three phases: } \\
\text { 1- measuring sound levels; 2- } \\
\text { implementing noise reduction } \\
\text { interventions: Voice reduction } \\
\text { strategies, implementation of } \\
\text { quiet time protocol, training of } \\
\text { personnel to perform processes } \\
\text { smoothly, training of person- } \\
\text { nel, parents, and visitors, use of } \\
\text { sound Gauges at different parts } \\
\text { of the section for sound control; } \\
\text { 3- Rechecking conditions }\end{array}$ & 2014 & $\begin{array}{l}\text { Wang, Aubertin, } \\
\text { Barrowman, } \\
\text { Moreau, Dunn, } \\
\text { Harrold }\end{array}$ & $\begin{array}{l}\text { To determine } \\
\text { whether imple- } \\
\text { mentation of a } \\
\text { noise reduction } \\
\text { policy followed } \\
\text { by the addition of } \\
\text { direct audit and } \\
\text { feedback reduces } \\
\text { noise levels in } \\
\text { a tertiary-level } \\
\text { NICU. }\end{array}$ \\
\hline $\begin{array}{l}\text { There was little change in noise } \\
\text { reduction. Sound levels decreased } \\
\text { from } 71-48 \text { to } 64-54 \mathrm{~dB} \text {. }\end{array}$ & $\begin{array}{l}\text { Identification of sources of } \\
\text { sound production, measure- } \\
\text { ment of sound levels before and } \\
\text { after noise reduction interven- } \\
\text { tions, meetings } \\
\text { Conferencing training in } 14 \\
\text { sessions }\end{array}$ & 2015 & $\begin{array}{l}\text { Carlos Carvalhais, } \\
\text { Joana Santos, } \\
\text { Manuela Vieira da } \\
\text { Silva \& ana Xavier }\end{array}$ & $\begin{array}{l}\text { To develop, } \\
\text { implement, and } \\
\text { evaluate the } \\
\text { effectiveness of a } \\
\text { Training Program } \\
\text { (TP) on noise } \\
\text { reduction in a } \\
\text { NICU }\end{array}$ \\
\hline Reduced noise by $3-4 \mathrm{~dB}$ & $\begin{array}{l}\text { Measurement of sound levels } \\
\text { during } 3 \text { weeks before and after } \\
\text { noise reduction interventions } \\
\text { and comparison with standard } \\
\text { levels, correction of department } \\
\text { structure and personnel training }\end{array}$ & 2015 & $\begin{array}{c}\text { Adriana Nieto- } \\
\text { Sanjuanero1, José } \\
\text { Quero-Jiménez, } \\
\text { Daniel Cantú-More- } \\
\text { no, Isaías Rodríguez- } \\
\text { Balderrama1, } \\
\text { Fernando Montes- } \\
\text { Tapia, Nadina Rubio- } \\
\text { Pérez, Consuelo } \\
\text { Treviño-Garza and } \\
\text { Manuel de la O- } \\
\text { Cavazos }\end{array}$ & $\begin{array}{l}\text { To determine the } \\
\text { noise levels of } \\
\text { different areas } \\
\text { responsible for } \\
\text { newborn care, } \\
\text { develop interven- } \\
\text { tion strategies } \\
\text { to decrease the } \\
\text { noise, and evalu- } \\
\text { ate its effective- } \\
\text { ness. }\end{array}$ \\
\hline $\begin{array}{l}\text { Reduced sound levels by about } 12 \text { - } \\
20 \mathrm{~dB} \text { at different locations }\end{array}$ & $\begin{array}{l}\text { Measurement of sound } \\
\text { levels in different parts of the } \\
\text { department during busy hours, } \\
\text { selection of trainer partner } \\
\text { through pre-test, training of per- } \\
\text { sonnel in different groups, the } \\
\text { re-examination of sound levels, } \\
\text { and post-test. }\end{array}$ & 2015 & $\begin{array}{l}\text { Azam Biabanaki- } \\
\text { goortani, Mahboo- } \\
\text { beh Namnabati, } \\
\text { Zahra Abdeyazdan, } \\
\text { Zohreh Badii }\end{array}$ & $\begin{array}{l}\text { To evaluate the } \\
\text { effect of peer } \\
\text { education on } \\
\text { the performance } \\
\text { of staff in noise } \\
\text { management in } \\
\text { the NICU }\end{array}$ \\
\hline
\end{tabular}




\section{Search strategy}

A literature search was conducted from 2012 to 2020 using Medline, Embase, CINAHL, SID IranDoc, and Magiran databases. The search words used were preterm infant, noise, and neonatal intensive care unit. Articles on sound levels and noise reduction interventions conducted at NICU were included. Conference proceedings and gray literature were also included. The articles were selected if they were in Persian/English languages, and interventional, or quasi-experimental in design. A total of 26 articles were found on noise levels, effects of noise enhancement, and noise reduction techniques; 19 articles included no interventions to reduce the noise in NICU and were excluded.

\section{Data collection and analysis}

Title screening was carried out by the first author based on the agreed, pre-piloted structured forms. Full-text articles were assessed for eligibility by other reviewers with agreement by consensus. The included studies were assigned a grade based upon their level of evidence and critically appraised using several tools (Burns, Rohrich \& Chung 2011; Evans 2003). Meta-analysis was not undertaken due to insufficient numerical data (Moher et al. 2016). Finally, six articles investigating different types of noise reduction techniques were reviewed. Papers that met the inclusion criteria were assessed in terms of performance and effectiveness of noise reduction interventions.

\section{Results}

The results are shown in Table 1.

\section{Discussion}

The noise level in the NICU consistently exceeds the recommended standards. Despite all interventions, the sound levels remained high. Noise reduction interventions were performed in the studied articles. The interventions used in the reviewed articles were the training of personnel and parents, changes in ward structure, use of low noise equipment, use of acoustics to alert loudspeakers, the implementation of quiet hours' protocol, care of infants in separate rooms, and use of earplugs.

The studies that assessed interventions found that continuous education was an important factor to reinforce suitable noise levels. The redesign of the NICU room has been recognized as one of the critical factors in maintaining a sound standard level. These findings led to effective strategies targeted environmental and behav- ioral modifications. Recent studies have shown that both structural changes and staff education have a significant impact on reducing NICU noise levels.

Implementing interventions to reduce noise levels may be attainable but requires a change in culture. Also, parents of newborns in NICUs will need education and reminders to maintain an appropriate level of silence within this environment. Proper placement of required equipment and careful evaluation of alarms are necessary. The implementation of such interventions should not inhibit the quality of care provided to this fragile population, but it should solely enhance it. Based on this review, nurses have a crucial role as leaders in affecting practice change to improve outcomes for the fragile population. Further studies focusing on implementing noise reduction strategies could enhance our knowledge base.

\section{Ethical Considerations}

\section{Compliance with ethical guidelines}

All Ethical considerations in this systematic review article were observed. Our reference was the rticle of "Ethical Considerations of Conducting Systematic Reviews in Educational Research" by Suri (2020).

\section{Funding}

The present paper was extracted from the Master thesis of the first author from Department of Neonatal and Pediatric Nursing, School of Nursing \& Midwifery , Iran University of Medical Sciences, Tehran.

\section{Authors' contributions}

Conceptualization, Original draft: Nasrin Gholami; Review and editing: Leili Borimnejad; Methodology: Reza jafari.

\section{Conflict of interest}

The authors declared no conflicts of interest.

\section{Acknowledgments}

The authors appreciate Iran University of Medical Sciences for its financial support. 


\section{References}

Abdeyazdan, Z., Ghassemi, S. \& Marofi, M., 2014. The effects of earmuff on physiologic and motor responses in premature infants admitted in neonatal intensive care unit. Iranian Journal of Nursing and Midwifery Research, 19(2), pp. 107-12. [PMID] [PMCID]

Aggarwal, D., et al., 2019. Turn down the volume: A study of excessive sound levels in the neonatal intensive care unit. Pediatrics, 144(2), p. 693. https:/ / pediatrics.aappublications. org/content/144/2_MeetingAbstract/693

Ahamed, M. F., et al., 2017. Noise reduction in the neonatal intensive care unit: A quality improvement initiative. American Journal of Medical Quality, 33(2), pp. 177-84 [DOI:10.1177/1062860617711563] [PMID]

Almadhoob, A. \& Ohlsson, A., 2015. Sound reduction management in the neonatal intensive care unit for preterm or very low birth weight infants. Cochrane Database Systematic Review, 1, p. CD010333. [DOI:10.1002/14651858.CD010333. pub3] [PMID]

Aita, M., et al., 2013. Intervention minimizing preterm infants' exposure to NICU light and noise. Clinical Nursing Research, 22(3), pp. 337-58. [DOI:10.1177/1054773812469223] [PMID]

Blackburn, S., 1998. Environmental impact of the NICU on developmental outcomes. Journal of Pediatric Nursing, 13(5), pp. 279-89. [DOI:10.1016/S0882-5963(98)80013-4]

Burns, P. B., Rohrich, R. J. \& Chung, K. C., 2011. The levels of evidence and their role in evidence-based medicine. Plastic and Reconstructive Surgery, 128(1) pp. 305-10. [DOI:10.1097/ PRS.0b013e318219c171] [PMID] [PMCID]

Calikusu Incekar, M. \& Balci, S., 2017. The effect of training on noise reduction in neonatal intensive care units. Journal for Specialists in Pediatric, 22(3), e12181. [DOI:10.1111/ jspn.12181] [PMID]

Carvalhais, C., et al., 2018. Noise in neonatal intensive care units: A short review. Euronoise, pp. 545-50. http://www. euronoise2018.eu/docs/papers/95_Euronoise2018.pdf

Duffy, A. R., et al., 2018. Comparison of hair cortisol levels and perceived stress in mothers who deliver at preterm and term. Biological Research for Nursing, 20(3), pp. 292-9. [DOI:10.1177/1099800418758952] [PMID]

Evans, D., 2003. Hierarchy of evidence: A framework for ranking evidence evaluating healthcare interventions. Journal Of Clinical Nursing, 12(1), pp. 77-84 [DOI:10.1046/j.13652702.2003.00662.x] [PMID]

Fernández Zacarías, F., et al., 2018. Noise level in neonatal incubators: A comparative study of three models. International Journal of Pediatric Otorhinolaryngology, 107, pp. 150-4. [DOI:10.1016/j.ijporl.2018.02.013] [PMID]

Lan, H. Y., et al., 2017. Factors associated with preterm infants' circadiansleep/wake patterns at the hospital. Clinical Nursing Research, 28(4), pp. 456-72. [DOI:10.1177/1054773817724960] [PMID]

Jeong, I. S., et al., 2014. Perceptions on pain management among Korean nurses in neonatal intensive care units. Asian Nursing Research, 8(4), pp. 261-6. [DOI:10.1016/j. anr.2014.05.008] [PMID]
Eggermont, J. J., 2017. Brain plasticity and perceptual learning Hearing Loss, pp. 37-69. [DOI:10.1016/B978-0-12-805398 0.00002-5]

Knutson, A. J., 2012. Acceptable noise levels for neonates in the neonatal intensive care unit [Internet]. Cited 1 August 2010 http:/ /digitalcommons.wustl.edu/pacs_capstones/643

Manske, R. L., 2017. Interventions to reduce the effects of ICU noise in peterm neonates [BA. theses] Orlando: University of Central Florida. https:/ / stars.library.ucf.edu/honorstheses/227/

Meredith, J. M., Jnah, M. \& Newberry, D., 2017. The NICU Environment: Infusing single-family room benefits into the open-bay setting. Neonatal Network, 36(2), pp. 69-76 [DOI:10.1891/0730-0832.36.2.69] [PMID]

Moher, D., et al., 2016. PRISMA for systematic review protocols (PRISMA-P) [Internet]. Cited 1 August 2020, http:// www.prisma-statement.org/Extensions/Protocols.aspx

Reyhani, T., et al., 2016. Evaluation of the effect of nest posture on the sleep-wake state of premature infants. Evidence Based Care Journal, 6(1), pp. 29-36. [DOI:10.22038/EBCJ.2016.6713]

Santos, J., et al., 2018. Assessment and characterization of sound pressure levels in Portuguese neonatal intensive care units. Archives of Environmental \& Occupational Health, 73(2), pp. 121-7. [DOI:10.1080/19338244.2017.1304883] [PMID]

dos Santos, B. R., et al., 2015. Effect of "quiet time" to reduce noise at the neonatal intensive care unit. Escola Anna Nery, 19(1), pp. 102-6. [DOI:10.5935/1414-8145.20150014]

Smith, S. W., Ortmann, A. J. \& Clark, W. M., 2018. Noise in the neonatal intensive care unit: A new approach to examining acoustic events. Noise and Health, 20(95), pp. 121-30. [DOI:10.1016/j.pedn.2015.10.011] [PMID] [PMCID]

Shimizu, A. \& Matsuo, H., 2016. Sound environments surrounding preterm infants within an occupied closed incubator. Journal of Pediatric Nursing, 31(2), pp. e149-54. [DOI:10.1016/j.pedn.2015.10.011] [PMID]

Suri H. (2020) Ethical Considerations of Conducting Systematic Reviews in Educational Research. Systematic Reviews in Educational Research. pp 41-54. https://link.springer.com/ chapter/10.1007/978-3-658-27602-7_3 
This Page Intentionally Left Blank 